\title{
Response of growing pigs to different evaporative cooling systems
}

\author{
O. A. Adebiyi, and Muibi, M. A.
}

Department of Animal Science, University of Ibadan, Nigeria Corresponding Author: femibiyi01@gmail.com

\section{Abstract}

Study was conducted for seven weeks to compare the response of growing pigs to shower and wallow cooling systems. Growing cross breeds of Landrace $x$ Large White pigs (weight 20$25 \mathrm{~kg}$ ) were used. Treatment 1,2 and 3 were pigs without shower/wallow (control), pigs on wallow and pigs under shower, respectively. Forty-eight pigs comprising four pigs/replicate were replicated four times to the three treatments in a completely randomized design. The shower was activated for 5 minutes every hour from 11 am to 5 pm. During the period, the performance response, physiological parameter, temperature humidity indexes, microbiological and behavioral response of the growing pigs were observed. Significant differences were observed in the final weight of pigs in $T 3(49.50 \mathrm{~kg})$ compared to pigs in TI $(46.75 \mathrm{~kg})$ and T2 $(46.00 \mathrm{~kg})$. Although, pigs in T1 had the highest significant feed intake of $14.15 \mathrm{~kg}$ compared to $10.81 \mathrm{~kg}$ and $10.38 \mathrm{~kg}$ that were observed for pigs in $T 2$ and $T 3$ respectively, the feed conversion ratio of pigs in T3 (3.82) was better. The temperature humidity index in the pen suggested that the pigs were at intense heat stress, thus requiring cooling (THI ranged from 81.12 to 86.39). The respiratory rate of the pigs ranged from approximately $41 \mathrm{~min}^{-1}$ to $51 \mathrm{~min}^{-1}$ while the weekly rectal temperatures ranged from $37.3^{\circ} \mathrm{C}$ to $39.4^{\circ} \mathrm{C}$ in all the treatments. The microbial analysis of the water in wallow and shower showed an increase in microbial population to be $26.0 \times 10^{4} \pm 3.54$ and $12.0 \times 10^{4} \pm 1.32$ while the fungi populations were $2.0 \times 10^{4} \pm 0.86$ and $1.0 \times 10^{4} \pm 0.57$ respectively. Pigs in T1 were found to exhibit more habitual lateral lying position, increased frequency of visiting water trough and defecating in resting areas. Huddling, defecating in wallow and frequency of using wallow was predominant in T2 pigs. It can be concluded that pigs in wallows may be more predisposed to infectious diseases due to high microbial load, however; pigs under shower responded positively to cooling via improved performance.

Keywords: Wallow, performance, temperature humidity index, behavior, microbial

\section{Introduction}

A major constraint in pig production is thermal stress. This is because pigs lack functional sweat glands, do not pant well and have large deposit of subcutaneous fat under their skin when compared to other animals. All farm pigs experience heat stress in temperate region, in summer and in tropical areas all the year round (Huynh and Aarnink, 2005). Larger swine (pigs in gestation, farrowing, breeding and finishing phases of production) are mostly affected due to their size. The temperature requirement of pigs varies with age, size, feeding level, health and environmental conditions. Like other homeotherms, pigs must maintain a constant core body temperature of $39^{\circ} \mathrm{C}$ for proper biological functioning (Huynh and Aarnink, 2005). However, heat production in animals result from metabolic activities and absorption from the environment (Webster, 1991). The pig's thermal strategies serve to control the transfer of energy between the pigs and its environment (Aarnink et al., 1996). Excessive heat must be dissipated to the environment to maintain normal temperature (Souza, 2009).

Heat stress occurs when temperature exceeds the upper critical temperature of 
thermoneutral zone (Black et al., 1993). Thermoneutral zone is the range of temperatures between the pig's lower critical temperature (LCT) and upper critical temperature (UCT) (Webster, 1991). LCT is the temperature below which pigs must increase metabolic heat production to maintain its body temperature (Webster, 1991). Below LCT, pigs experience cold stress thereby increasing heat production (Huynh and Aarnink, 2005). The UCT is the temperature above which swine must rely on evaporative cooling to maintain body temperature (Webster, 1991). Heat stress impairs animals' welfare, environment and economics of pig industry (Huynh et al., 2005). Pigs alter their behaviour and physiology to increase heat loss and reduce heat production (Aarnink et al., 1996). Behavioural signs include reduced feed intake, increased water intake, changes in lying posture, decrease in animal activity and wallowing (Aarnink et al., 1996). Physiological signs include increased respiratory rate and increased rectal temperature (Huynh and Aarnink, 2005). These responses are at the expense of production and reproductive performances. Pigs depend on heat dissipation through sensible and latent heat transfer (Huynh and Aarnink, 2005).

Cooling systems in piggery alleviates the effect of heat stress and improves productivity (Huynh and Aarnink, 2005). Cooling strategies include increased water supply, wet skin cooling, nutritional adjustment, adequate ventilation, increased floor space, adequate insulation and provision of shades. Furthermore, most advanced cooling systems are complicated, costly and increase humidity in animal house (Huynh et al., 2005). Evaporative cooling from body surface through artificial surface wetting reduces heat stress. For a small holder farmer, alternative cooling system for pigs is a shower or a wallow
(Huynh et al., 2005). Wallow is an effective means of cooling pigs but unsanitary due to microbial build up in the wallow. Sprinkling pigs periodically and allowing them to dry out between wettings is more effective (Huynh et al., 2005). This study was carried out to investigate the effect of shower and wallow cooling on the behavioural, physiological and performance responses and alsothe effect of microbial population in a wallow.

\section{Materials and methods}

The study was carried out in the Swine unit of the Teaching and Research Farm, University of Ibadan between October, 2015 and December, 2015. Forty-eight healthy, growing cross bred pigs (Landrace $x$ Large White) of $20-25 \mathrm{~kg}$ gilts were used. Each treatment was replicated four times with four pigs per replicate in a completely randomized design. Experimental diet was formulated to meet the nutrient requirements of the growing pigs (NRC 1987) $(2600 \mathrm{Kcal} \mathrm{ME}, 18 \%$ Protein, $0.6 \%$ Calcium, $0.45 \%$ Phosphorus, $0.80 \%$ Lysine). The treatments were: treatment 1 (TI): Pen without wallow/shower, treatment 2 (T2): Pen with wallow and treatment 3 (T3): Pen with shower. The pigs were preconditioned for one week to acclimatize to the new environment and were tagged for identification purposes. Vaccination and medications were administered accordingly. Ad libitum feeding of standard diet and water supply were administered. The wallow was filled with clean water throughout and shower was activated 5 minutes every hour from $11.00 \mathrm{am}-5.00 \mathrm{pm}$ on daily basis.

\section{Data collection}

\section{Physiological data}

Physiological data were collected weeklyaccording toHuynh et al.(2005). 
Skin temperature (ST) was measured using radiant thermometer. The respiratory rate (RR) was measured by counting number of flank movement using a stopwatch and the rectal temperature (RT) was measured using digital thermometer inserted $50 \mathrm{~mm}$ into the rectum.

\section{Meterological data}

Pen temperature and relative humidity was measured weekly using thermo-hygrometer on hourly basis. Temperature- humidity index (THI) was calculated using National Oceanic and Atmospheric Administration (NOAA), 1976 formula:

$\mathrm{THI}\left({ }^{\circ} \mathrm{C}\right)=0.8 \mathrm{~T}+(\mathrm{RH} / 100) \times(\mathrm{T}-14.3)+$ 46.4

Where $\mathrm{T}=$ ambient temperature in ${ }^{\circ} \mathrm{C}$

$\mathrm{RH}=$ relative humidity $(\%)$

THI $\leqslant 74$ is safe, $74<\mathrm{THI}<79$ is critical, $79 \leqslant \mathrm{THI}<84$ is dangerous and $\mathrm{THI} \geqslant 84$ is emergency

\section{Behavioural data}

Observations were made via mounted CCTV camera according to the procedure (Huynh et al., 2005). The behavioural parameters measured were: lying positions (lateral lying), huddling, excretion (Relative frequency of defecating and urination in wallow) and frequency of using wallow/shower

\section{Performance data}

Data on daily feed intake, average daily weight gain and feed efficiency were taken

\section{Microbial Analysis}

Water samples from the wallow and shower were collected and analysed for the microbial load by standard pour plate method.

\section{Statistical analysis}

Data were subjected to one way analysis of variance and descriptive statistics

\section{Results}

Table 1 showed the Performance response of growing pigs under different cooling systems. The result revealed that gilts of average weight ranging from $26.50-27.25$ $\mathrm{kg}$ were randomly allocated to the respective treatments. The final weight, weight gain, weight change/week of pigs in T3 was significantly $(p<0.05)$ higher than $\mathrm{T} 1$ and $\mathrm{T} 2$. However, the average feed intake of pigs in TI was significantly $(p<0.05)$ higher than their counterparts in T2 and T3. Nevertheless, the feed conversion ratio of pigs in T3 was significantly $(p<0.05)$ better than those in $\mathrm{T} 1$ and T2. Figure 1 shows the temperaturehumidity index of the experimental house as calculated from National Oceanic and Atmospheric Administration (NOAA), 1976 formula: $\mathrm{THI}\left({ }^{\circ} \mathrm{C}\right)=0.8 \mathrm{~T}+(\mathrm{RH} / 100)$ $\times(T-14.3)+46.4$. This figure suggests that the THI was on the high side ranging from 81 to 86 .The respiratory rate of the growing pigs (Figure II) ranged from approximately $41 \mathrm{~min}^{-1}$ to $51 \mathrm{~min}^{-1}$ over a period of seven weeks. There was no significant difference $(p>0.05)$ in the respiratory rate of in the treatment groups. The rectal temperature of the growing pigs in the three treatments (Figure III) ranged from approximately $37.3^{\circ} \mathrm{C}$ to $39.4^{\circ} \mathrm{C}$, showed no significant variation $(p>0.05)$. Figure IV shows the skin temperature of the growing pigs which ranged from $36.2^{\circ} \mathrm{C}$ to $37.3^{\circ} \mathrm{C}$ and over a period of seven weeks. There was no significant $(p>0.05)$ difference in skin temperature in week one, two, four, five and seven. However, in week 3, pigs in treatment 2 i.e wallow had much lower skin temperature compared to pigs in treatments 1 and 3 . The average bacterial in the shower and drinking water (Table II) of pigs in treatments 1 and 3 was $12 \times 10^{-4} \pm 1.32 \mathrm{cfu} / \mathrm{g}$ 
while in the wallow (T2), the average bacterial count was $26 \times 10^{-4} \pm 3.54 \mathrm{cfu} / \mathrm{g}$. There was no significant $(p>0.05)$ difference in the average fungal count. Table III shows the behaviour of the growing pigs under the cooling systems. Lying behaviour, frequency of defecating and frequency of visiting water trough was significantly highest $(51 \%, 50 \%$ and $51 \%$ respectively) in pigs without additional cooling relief while pigs under shower and wallow used their respective cooling system equally.

\section{Discussion}

In this study, the temperature humidity index of the animal house as determined by National Oceanic and Atmospheric Administration (NOAA), 1976 formula: $\mathrm{THI}\left({ }^{\circ} \mathrm{C}\right)=0.8 \mathrm{~T}+(\mathrm{RH} / 100) \times(\mathrm{T}-14.3)+$ 46.4 suggested that the THI was on the high side ranging from 81 to 86 . This value (THI $\leqslant 74$ is safe, $74<\mathrm{THI}<79$ is critical, $79 \leqslant$ $\mathrm{THI}<84$ is dangerous and $\mathrm{THI} \geqslant 84$ is emergency) revealed that the animals were either at a dangerous or emergency state where alternative cooling would be required. However, supplemental cooling in the form of shower and wallow was provided for pigs in $\mathrm{T} 2$ and $\mathrm{T} 3$ with while pigs in $\mathrm{T} 1$ served as the negative control (without supplemental cooling).

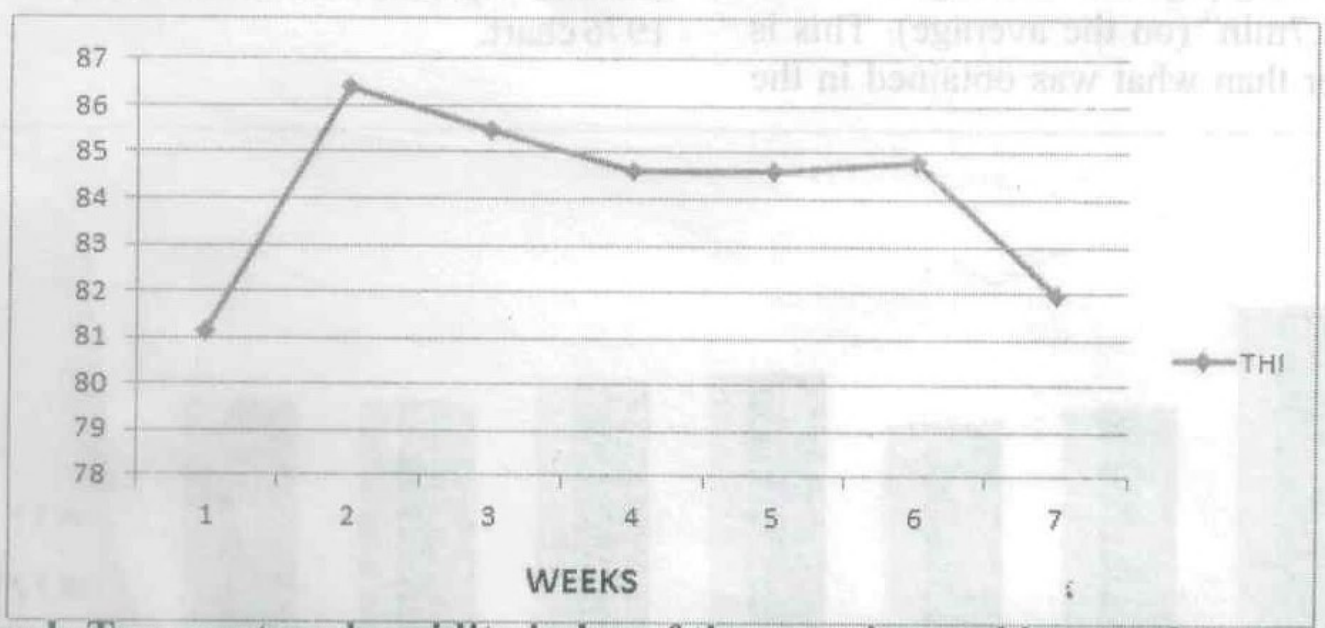

Figure I: Temperature humidity index of the experimental house of the growing pigs

The performance table showed that initial weight of pigs in all the treatment groups were within the range of 26.50 and $27.25 \mathrm{~kg}$. The pigs with shower (T3) had significantly the highest final weight of $49.50 \mathrm{~kg}$, weight gain of $25.33 \mathrm{~kg}$ and weight change per week of $2.83 \mathrm{~kg}$ compared to pigs in T1 and T2 which were without cooling and with wallow respectively. The average feed intake of pigs on T1 was significantly higher than T2 and T3 with $10.81 \mathrm{~kg}$ and $10.38 \mathrm{~kg}$ respectively which were not significantly different from each other.
However, with lower average feed intake, pigs under the shower were able to optimize performance through improved final weight, weight gain and a much significantly lower feed conversion ratio of 3.82 compared to T1 (5.65) and T2 (4.65). This also result also showed that increase in the feed intake may not translate into better animal performance especially for pigs that are under heat stress. The poor performance of pigs under the wallow could also be attributable to the high microbial load in the water which eventually affected feed utilization. 
Adebiyi and Muibi

Table 1: Performance response of growing pigs under different cooling systems

\begin{tabular}{lllll}
\hline Parameters & T1 & T2 & T3 & SEM \\
\hline Initial weight $(\mathrm{kg})$ & 26.75 & 27.25 & 26.50 & \\
Final weight $(\mathrm{kg})$ & $46.75^{\mathrm{b}}$ & $46.00^{\mathrm{b}}$ & $49.50^{\mathrm{a}}$ & 2.68 \\
Weight gain $(\mathrm{kg})$ & $20.00^{\mathrm{b}}$ & $18.75^{\mathrm{c}}$ & $25.33^{\mathrm{a}}$ & 2.98 \\
Weight change/week & $2.50^{\mathrm{b}}$ & $2.34^{\mathrm{c}}$ & $2.83^{\mathrm{a}}$ & 0.15 \\
(kg) & & & & \\
Average feed intake $(\mathrm{kg})$ & $14.13^{\mathrm{a}}$ & $10.81^{\mathrm{b}}$ & $10.38^{\mathrm{b}}$ & 0.01 \\
FCR & $5.65^{\mathrm{a}}$ & $4.65^{\mathrm{b}}$ & $3.82^{\mathrm{b}}$ & 0.26 \\
\hline
\end{tabular}

$a, b, c$ means within rows with unlike superscripts are significantly different from each other $(p<0.05)$, SEM: standard error of mean.TI: Pen without wallow /shower T2: Pen with wallow T3:Pen with shower

The respiratory rate (RR) and rectal temperature of the three treatment groups over a period of seven weeks were not significantly different. As reported by Huynh et al. (2006), a normal respiratory rate of growing pigs should range between 29.1 to $32.7 \mathrm{~min}^{-1}$ (on the average). This is quite lower than what was obtained in the present research which ranged from 41 to $50 \mathrm{~min}^{-1}$. A higher RR above the expected RR corroborates the deduction of the dangerous or emergency state of the animals as revealed by National Oceanic and Atmospheric Administration (NOAA), 1976 chart.

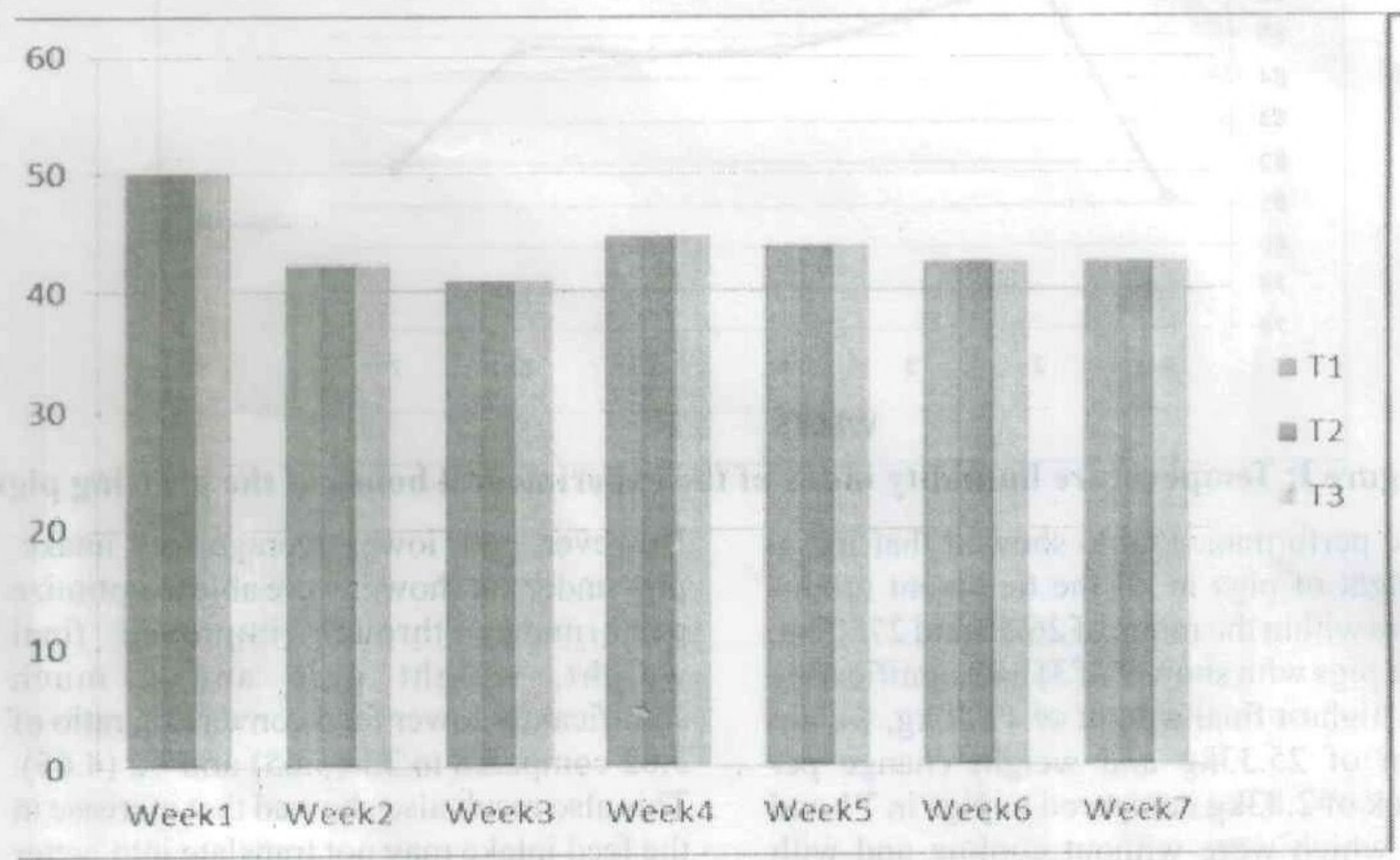

Figure II: Weekly respiratory rate of growing pigs 


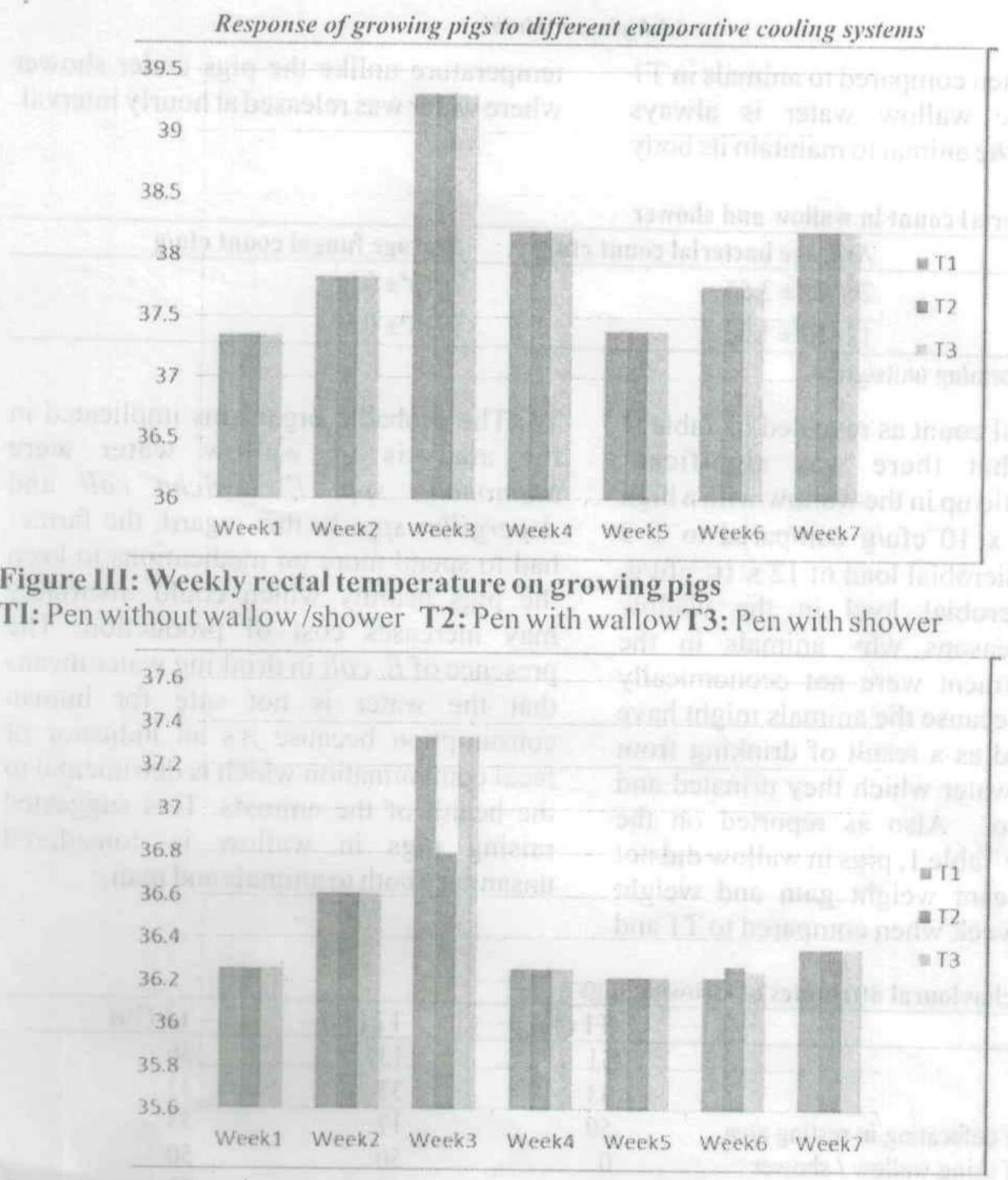

Figure IV: Weekly skin temperature of growing pigs

TI: Pen without wallow/shower T2: Pen with wallow T3: Pen with shower

The skin temperature (ST) ranges of approximately $36.2^{\circ} \mathrm{C}$ to $37.3^{\circ} \mathrm{C}$ means that the deep body temperature revealed by the rectal temperature (RT) reflected on the skin temperature. This value of ST is slightly higher than that of previous studies. Geer et al. (1987) reported that the comfort ST of homoeothermic animals ranges from $32^{\circ} \mathrm{C}$ to $35^{\circ} \mathrm{C}$. This is similar to the findings of Huynh et al. (2006) who reported that within a temperature range of 16 to $22^{\circ} \mathrm{C}$, the ST of $60 \mathrm{~kg}$ ad lib fed, grouped housed pigs ranged from 33 to $35^{\circ} \mathrm{C}$. The high ST of pigs in the present study showed that pigs raised in tropical conditions not only reacted to heat stress by RR but also by RT and ST. This is because vasodilation of epidermal blood vessels atlows deep body heat load to be dissipated more easily to the cooler environment. Moreso, a reduction in ST of growing pigs in wallow suggest that the wallow was able to ameliorate the effect of 


\section{Adebiyi and Muibi}

heat stress when compared to animals in T1 and T3. The wallow water is always available for the animal to maintain its body temperature unlike the pigs under shower where water was released at hourly interval.

Table II: Bacterial count in wallow and shower

\begin{tabular}{lll}
\hline Sample & Average bacterial count cfu/g & Average fungal count cfu/g \\
\hline Wallow & $26 \times 10^{4} \pm 3.54$ & $2 \times 10^{4} \pm 0.86$ \\
Shower & $12 \times 10^{4} \pm 1.32$ & $1 \times 10^{4} \pm 0.57$ \\
\hline
\end{tabular}

cfu/g: colony forming units/gram

The microbial count as revealed in Table II indicated that there was significant microbial build up in the wallow with a high value of $26 \times 10^{-4} \mathrm{cfu} / \mathrm{g}$ compared to T 3 which had microbial load of $12 \times 10^{-1} \mathrm{cfu} / \mathrm{g}$. A high microbial load in the wallow suggested reasons why animals in the wallow treatment were not economically productive because the animals might have been infected as a result of drinking from the wallow water which they urinated and excreted into. Also as reported on the performance Table 1, pigs in wallow did not have significant weight gain and weight change per week when compared to TI and
T3. The probable organisms implicated in the analysis of wallow water were Salmonella spp, Eschericha coli and Aspergillus spp. In this regard, the farmer had to spend more on medications to keep the pigs healthy which could invariably may increases cost of production. The presence of $E$. coli in drinking water means that the water is not safe for human consumption because it's an indicator of fecal contamination which is detrimental to the health of the animals. This suggested raising pigs in wallow is considered unsanitary both to animals and man.

Table III: Behavioural attributes of Growing pigs

\begin{tabular}{llll} 
& T1 (\%) & T2 $(\%)$ & T3 $(\%)$ \\
\hline Lateral lying & 51 & 13 & 36 \\
Huddling & 33 & 33 & 33 \\
Frequency of defecating in resting area & 50 & 17 & 33 \\
Frequency of using wallow / shower & 0 & 50 & 50 \\
Frequency of visiting water trough & 51 & 12 & 37
\end{tabular}

TI: Pen without wallow/shower T2: Pen with wallow T3: Pen with shower

The behavioral data collected (Table III) showed that pigs in $\mathrm{T} 1 \mathrm{had}$ the highest lying behavior compared to those in $\mathrm{T} 2$ and $\mathrm{T} 3$. According to Huynh et al. (2005), increasing lying behavior indicates heat stress because lying animals avoid expending energy on movement and therefore reduce their total heat load. Huynh et al. (2005) reported that lying location changes with increasing temperature, when room temperature is above $30^{\circ} \mathrm{C}$, the percentage of lying pigs on the slatted floor peaked. At high temperatures, $90 \%$ of pigs prefer to lie and also they cool themselves by wallowing in excrement. The pig will lie down in a fully recumbent position with their limbs extended, in order to be able to transfer as much heat as possible to the environment (Close et al., 1981). During summer, low air velocity combined with high inside temperature caused a greater incidence of animals lying in the dunging 
Response of growing pigs to different evaporative cooling systems

area, bad pen hygiene, The huddling behavior of the growing pigs were similar. This is a common attribute of pigs in all treatment groups especially during the early hours of the day and late in the evening when the temperature is low. Pigs in T1 defecated more than their counterpart in T2 and T3. This isprobably they were heat stressed and chose to reduce their digestive content. Pigs in T2 with wallow excreted more in the wallow than in the resting areas of the pen when compared to those in T1 and T3. In previous studies, Aarnink et al. (2001) and Huynh et al. (2004, 2005) showed that $60 \mathrm{~kg}$ pig provided with $1 \mathrm{~m}$ floor space (slatted floor) in hot conditions did not discriminate between resting and defecating areas at all. Hacker et al. (1994) reported that the pig's basic instinct is to excrete in a wet, cool place. These findings explained the frequency of excretion in wallow. This is undesirable with respect to hygiene and health. The frequency of using wallow and shower was similar for treatments 2 and 3 because the pigs responded positively to the cooling by regularly responding to shower and frequent use of wallow. Due to the absence of cooling relief, pigs in TI visit the water trough regularly to compensate for not having any cooling relief. This becomes imperative in order to cool their body unlike $\mathrm{T} 2$ and $\mathrm{T} 3$ that had additional cooling relief.

\section{Conclusion}

It can be concluded from this study that high THI influenced the behavior, physiology and performance of growing pigs. Pigs in wallows could be more predisposed to diseases due to microbial load in the wallow water which the animal drink and bathe in. Lying behavior, excretion in resting areas and regular visits to water trough increased with increase in temperature. Shower cooling positively ameliorated the effect of heat stress without fear of microbial infections.

\section{References}

Aarnink, A. J. A., Schrama, J. W., Verheijen, R. J. E. and Stefanowska, J. 2001. Pen fouling in pig houses affected by temperature. Pages 180-186 in Livestock Environment VI. Louisville, KY.

Aarnink, A. J.A., Van den Berg, J., Keen, A., Hoeksma, P., Verstegen, M. W. A. 1996. Effect of slatted floor area on ammonia emission and on the excretory and lying behaviour of growing Digs. Irish J. Agric. Res. 64:299-310

Black, J. L., Mullan, B. P., Lorschy, M. L., Giles, L. R., 1993. Lactation in the sow during heat stress. Livestock Production Science, 35: 153-170

Close, W. H., Heavens, R. P., Brown, D., 1981. The effects of ambient temperature and air movement on heat loss from the pig. Animal Production, 32 (01), 75-84.

Geers, R., van der Hel, W., Verhagen, J., Verstegen, M., Goedscels, V., Brandsma, H., Henken, A., Scholler, J. and Berckmans, D. 1987. Surface temperatures of growing pigs in relation to the duration of acclimation to air temperature or draught. J. Thermal Biol. 12:249.-255

Hacker, R. R., Ogilviei, J. R., Morrison, W. D., Kainst, F. 1994. Factors affecting excretory behavior of pigs. J. Anim. Sci. 72:1455,-1460.

Huynh, T. T. T., Aarnink, A. J. A., Spoolder, M., Verstegen, M. W.A. and Kemp, B. 2004. Effect of Floor Cooling during high ambient 
temperatures on the lying behaviour and productivity of growing finishing pigs. American Society of Agricultural Engineers Vol. 47 (5): 1773-1782

Huynh, T. T. T., Aarnink, A. J. A., Verstegen, M. W. A., Gerritis W. J. J., Heetkamp M. N. W., Kemp B., Canh T.T. 2005. Effect of increasing temperatures on physiological changes in pigs at different relative humidities. Journal of Animal Science 83:13852-1396

Huynh, T. T. T., Aarnink, A. J. A. 2005. Heat stress in pigs Pig Progress pp. $30-32$

Huynh, T. T. T., Aarnink, A. J.A., Truong, C. T., Kemp, B. and Verstegen, M. W. A. 2006. Effects of tropical climate and water cooling methods on growing pigs'responses Livestock Science pp. $278-291$ ISSN: 1871-1413.
National Oceanic and Atmospheric Administration 1976. Livestock Hot Weather Stress. Operations Manual Letter c-31-76. Kansas City.

NRC, 1987. Predicting feed intake of food producing animals. National Academy Press, Washington, DC

Souza, L. 2009. How can heat stress affect production? The Pig site (the website for the global pig industry). A v a i l a b l e a $t$ http//www.pigsite.com

Webster, A. J. F. 1991. Metabolic responses of farm animals to high temperature. EAAP Publication, No. $55: 15-22$

Received: $17^{\text {th }}$ October, 2016 Accepted: $23^{\text {rid }}$ February, 2017 